\title{
Human $N$-acetylation genotype determination with urinary caffeine metabolites
}

\begin{abstract}
The human acetylation genotype was determined by measuring urinary caffeine metabolites by use of a modification of a previously published HPLC method. The problem of separation of 7 -methylxanthine (7X) from 1-methyluric acid (IU) in urine extracts was achieved by adding a phenyl column, in tandem with a $\mathrm{C}_{18}$ reverse-phase column, by means of a methanol:aqueous acetic acid gradient elution system. The urinary molar ratios of (AAMU)/(AAMU + 1U + 1X) and (AAMU)/(1X) were estimated in 20 subjects phenotyped with dapsone, with $100 \%$ concordance for the $[\mathrm{AAMU}] /[1 \mathrm{X}]$ ratio. A population study of $\mathbf{4 2}$ unrelated individuals exhibited trimodal distribution in acetylation capacity, consistent with the Hardy-Weinberg theory of population genetics. Definitive pedigree analysis of 16 families ( 75 subjects) resulted in significant similarity between the observed genotypic matings and those expected by classical Mendelian segregation. This noninvasive genotyping method promises to be useful in future investigation of the relationship between the human acetylation polymorphism and clinical disorders. (CLIN Pharmacol Ther 1990;47:470-7.)
\end{abstract}

\section{Anthony J. Kilbane, $\mathrm{MB}, \mathrm{BCh}^{\mathrm{a}}{ }^{\mathrm{L}}$ Lawrence K. Silbart, $\mathrm{PhD},{ }^{\mathrm{b}}$ Melanie Manis, $\mathrm{PhD},{ }^{\mathrm{c}}$ Inese Z. Beitins, MD, ${ }^{d}$ and Wendell W. Weber, MD, PhD Ann Arbor, Mich.}

Techniques employed in $\mathrm{N}$-acetylation phenotyping have, traditionally, required the subjects tested to consume predetermined doses of such drugs as isoniazid, ${ }^{1,2}$ sulfamethazine, ${ }^{3}$ sulfasalazine, ${ }^{4}$ dapsone, ${ }^{5,6}$ and procainamide. ${ }^{7}$ Multiple dose administrations, complex extraction processes, ethical constraints, reluctance by some to ingest these agents and hypersensitivity reactions in predisposed individuals were major disadvantages encountered when population studies were undertaken for more extensive assessment of the relationship between acetylator status and clinical disease. ${ }^{8,9}$

From the Departments of Pharmacology and Pediatrics and Communicable Diseases, University of Michigan Medical School.

Presented in part at the Annual meeting of the American Physiological Society/American Society for Pharmacology and Experimental Therapeutics, Oct. 9-13, 1988.

Supported in part by U.S. Public Health Service grant GM27028

Received for publication Aug. 17, 1989; accepted Oct. 8, 1989.

Reprint requests: Wendell W. Weber, $\mathrm{MD}, \mathrm{PhD}$, University of Michigan Medical School, Department of Pharmacology, Room 7445 Medical Science I, Ann Arbor, MI 48109-0626.

${ }^{\text {a}}$ Current address: Department of Internal Medicine, St. Joseph Mercy Hospital, Ann Arbor, MI 48106.

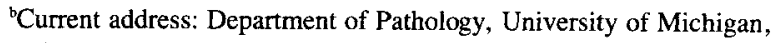
Ann Arbor, MI 48109.

'Current address: The Upjohn Company, Kalamazoo, MI 49008.

${ }^{d}$ Current address: Department of Pediatrics and Communicable Diseases, University of Michigan, Ann Arbor, MI 48109.

$13 / 1 / 18153$
Recent experience with caffeine as a test drug for determination of the human acetylator phenotype might circumvent some of the problems mentioned above, inasmuch as this universally available substance is consumed on a daily basis by a substantial number of people. ${ }^{10,11}$

The isolation ${ }^{12}$ and identification by $\mathrm{HPLC}^{13}$ of a urinary caffeine metabolite, 5-acetylamino-6-amino-3methyluracil (AAMU), and an additional unidentified acetylated metabolite, excreted in urine in varying concentrations depending on the acetylator phenotype, ${ }^{14}$ led to further evaluation of caffeine as a suitable substrate for investigation of the human acetylation polymorphism. This latter compound, identified as 5acetylamino-6-formylamino-3-methyluracil (AFMU), was proved to be a major uracilic metabolite of caffeine. ${ }^{15,16}$ Urinary concentration of AFMU was directly related to $N$-acetyltransferase enzyme activity ${ }^{17}$ and formed the basis for determination of the acetylator phenotype by use of the urinary molar ratio of AFMU to 1-methylxanthine (1X). ${ }^{18}$ Instability of AFMU and its spontaneous conversion to AAMU by deformylation with dilute sodium hydroxide led to quantitation of the urinary molar ratio of (AAMU)/(1X) to determine the acetylator phenotype.$^{19}$ AAMU was found to be more stable than its biologic precursor. In an attempt to separate homozygous from heterozygous rapid acetylators, the urinary molar ratio of 
(AAMU)/(AAMU + $1 \mathrm{U}+1 \mathrm{X})$ was measured in a selected population and reflected a trimodal distribution in $\mathrm{N}$-acetylation patterns. ${ }^{20}$

The purpose of the present study is, through studies of a random population combined with family pedigree analysis, to further investigate the urinary molar ratio of AAMU to products ( $1 \mathrm{U}$ and $1 \mathrm{X}$ ) of the 7-demethylation pathway of paraxanthine $(1,7-$ dimethylxanthine) metabolism, for future application as an acetylator genotyping method.

\section{METHODS}

Subjects. After receiving approval from the Human Resources Committee of the University of Michigan (Ann Arbor, Mich.), subjects in the study were requested to avoid food and beverages that contained methylxanthines for 48 hours or longer. Subjects then consumed a caffeine-containing drink, (e.g., coffee or cola) and supplied a urine sample 6 hours later. After adjustment of each urine sample to $\mathrm{pH} 3.5$ with $6 \mathrm{~N}$ hydrochloride, a $10 \mathrm{ml}$ aliquot was stored at $-20^{\circ} \mathrm{C}$ until assayed. Excluded from the study were individuals with idiosyncratic reactions (e.g., tachycardia, tremors, and insomnia) to caffeine. No other specific dietary restrictions were enforced. Three groups of individuals were then analyzed as follows: (1) Twenty healthy subjects, previously phenotyped with dapsone by use of the method of Carr et al., ${ }^{21}$ were selected and retested by use of the caffeine method; (2) a population study of 42 unrelated adult white persons from the local community was undertaken to estimate the gene frequency and to further evaluate the expected trimodal distribution pattern; and (3) informative family studies of patients with type I (insulin-dependent) diabetes mellitus, attending the pediatric endocrinology clinics at the University of Michigan hospitals, and their first-degree relatives, in addition to families living in the locality, were tested for acetylation capacity. A detailed pedigree analysis, consisting of 16 families (75 subjects), was undertaken to assess the Mendelian segregation patterns.

Material. Caffeine, 1-methyluric acid (1U), 1methylxanthine (1X), $N$-acetyl-p-amidophenol, benzyloxyurea, and 7-methylxanthine (7X) were obtained from Sigma Chemical Co. (St. Louis, Mo.) at the highest purity available. AFMU was supplied by Dr. W. Kalow (University of Toronto, Toronto, Ontario, Canada). All HPLC buffers were spectroscopic grade. AAMU was prepared by deformylation of AFMU with dilute sodium hydroxide.

Analytic procedures. Because of incomplete resolution of AFMU from interfering peaks in the early phase of the chromatogram with the $\mathrm{C}_{18}$ octyldecylsilane reverse-phase column, urinary AAMU concentration
A

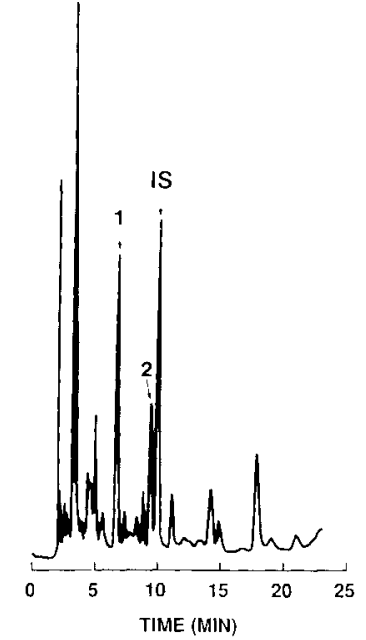

B

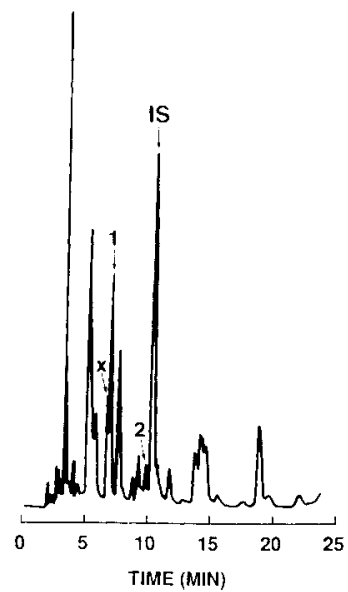

Fig. 1. HPLC chromatograms of solvent extracted urine from two individuals, $A$ and $B$, by use of the $C_{18}$ reverse-phase $5 \mu \mathrm{m}$ column and conditions described by Grant et al. ${ }^{17}$ Extracted urine from subject A shows satisfactory resolution of IU but that from subject $B$ is an example of incomplete separation of $1 \mathrm{U}$ from $7 \mathrm{X}$. Conditions: isocratic elution with $0.05 \%$ aqueous acetic acid/methanol $(88: 12, \mathrm{vol} / \mathrm{vol})$ at a flow rate of $1.2 \mathrm{ml}$ per minute and ultraviolet absorbance at $280 \mathrm{~nm}$. Retention times: 7 -methylxanthine $(\mathrm{X}), 6.6$ minutes; 1-methyluric acid (1), 6.8 minutes; 1-methylxanthine (2), 9.3 minutes; internal standard (IS), $N$-acetyl- $p$-amidophenol, 10.2 minutes.

was measured by the HPLC method of Tang et al. ${ }^{19}$ The stored urine samples were thawed and a $50 \mu \mathrm{l}$ aliquot was withdrawn and treated with $50 \mu \mathrm{l}$ of $0.2 \mathrm{~N}$ sodium hydroxide for 10 minutes at room temperature to achieve a final $\mathrm{pH}$ greater than 8 , for quantitative deformylation of AFMU to AAMU. Then $50 \mu \mathrm{l}$ of 0.2 $\mathrm{mol} / \mathrm{L}$ hydrochloride was added to neutralize excess base and $100 \mu \mathrm{l}$ of the internal standard, benzyloxyurea ( $1 \mathrm{mg} / \mathrm{ml}$ in $0.1 \%$ aqueous acetic acid) was added, from which a $20 \mu \mathrm{l}$ sample was injected onto a BioGel TSK-20 $(300 \times 7.5 \mathrm{~mm})$ size exclusion HPLC column (Richmond, Calif.). A Varian 5060 programmable HPLC solvent delivery system (Walnut Creek, Calif.) with a Rheodyne injector (Cotati, Calif.), Varian ultraviolet-100 detector, and a Spectrophysics SP4270 integrator (San Jose, Calif.) were used to perform the separation and quantitation. An isocratic elution with $0.1 \%$ aqueous acetic acid at $0.8 \mathrm{ml}$ per minute flow rate was maintained, and the column eluent ultraviolet absorption was monitored at $254 \mathrm{~nm}$. The identical protocol was performed with baseline urine samples that were spiked with known amounts of AAMU standards. 

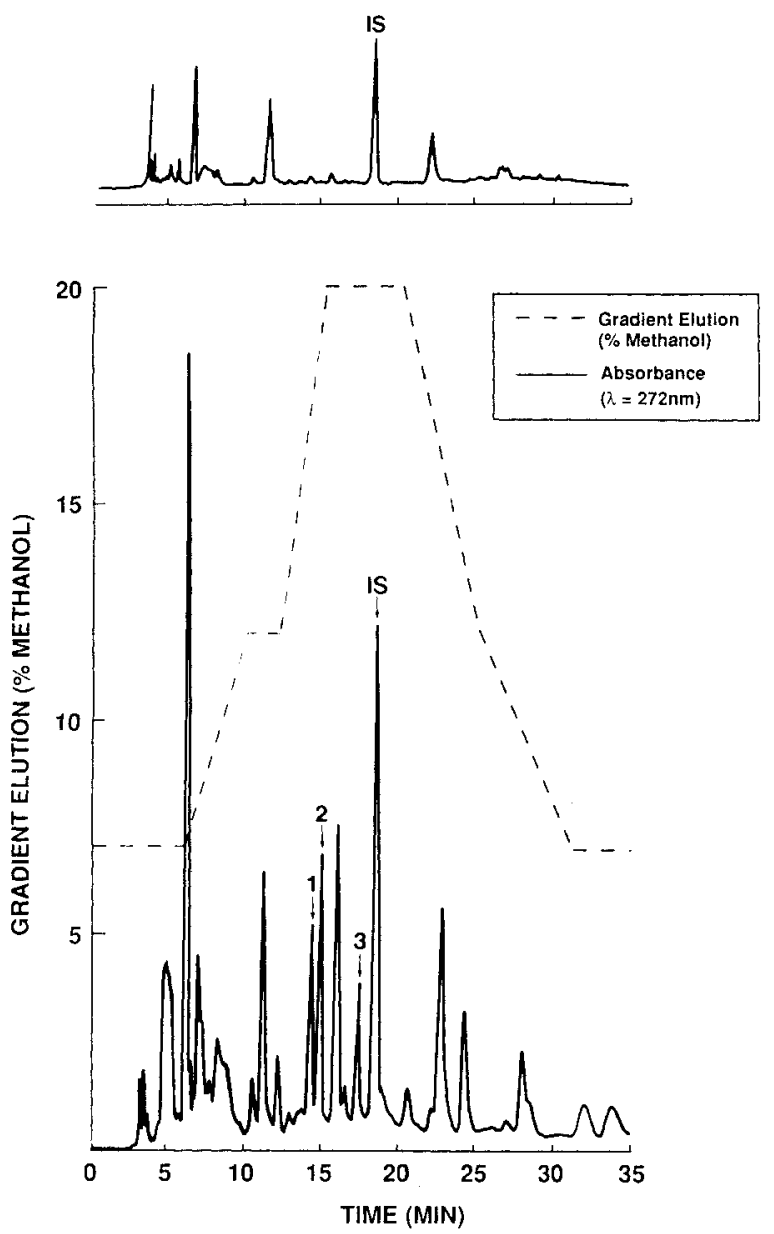

Fig. 2. HPLC chromatogram of solvent-extracted urine from an individual after a 48-hour abstinence from methylxanthinecontaining food and drink (upper tracing), and urine from the same individual 6 hours after caffeine ingestion (lower tracing). The aliquot of urine extract was injected onto a phenyl column in tandem with a $\mathrm{C}_{18}$ reverse-phase column. A gradient elution was performed as shown (broken line). Aqueous phase: $0.05 \%$ aqueous acetic acid/water; organic phase: methanol. Retention times: 1-methyluric acid (1), 14.6 minutes; 7-methylxanthine (2), 15.2 minutes; 1 methylxanthine (3) 17.7 minutes; internal standard (IS), $\mathrm{N}$ acetyl-p-amidophenol, 18.7 minutes.

Standard curves relating the integrated signal values (relative to the internal standard, benzyloxyurea) versus known amounts of AAMU standards, processed as above, were constructed. Subsequent urinary AAMU concentrations were calculated by interpolation from the linear standard curve.

By use of a $\mathrm{C}_{18}$ reverse-phase column under the HPLC conditions reported by Grant et al., ${ }^{17}$ difficulties in the separation of $1 \mathrm{U}$ from $7 \mathrm{X}$ were encountered in at least one third of the urine samples tested (Fig. 1), which persisted despite manipulation of the gradient conditions.

For quantitation of $1 \mathrm{U}$ and $1 \mathrm{X}$, a modification of the method of Grant et al. ${ }^{17}$ was used. To a $200 \mu \mathrm{l}$ urine sample was added $120 \mathrm{mg}$ ammonium sulfate, and the sample was then vortexed briefly in a $15 \mathrm{ml}$ Corex (Corning, Corning, N.Y.) tube. A $200 \mu \mathrm{l}$ aliquot of the internal standard, $N$-acetyl-p-amidophenol $(100$ $\mathrm{mg} / \mathrm{L}$ in chloroform) was added, followed by the addition of $6 \mathrm{ml}$ chloroform:isopropanol $(85: 15)$ and the mixture was vortexed for 30 seconds. After centrifugation at $2,500 \mathrm{~g}$ for 5 minutes at room temperature, the aqueous phase was removed and discarded, and the organic phase was evaporated to dryness with a gentle stream of nitrogen at $45^{\circ} \mathrm{C}$. The residue was redissolved in $800 \mu \mathrm{l}$ methanol $/ 0.05 \%$ aqueous acetic acid-water $(12: 88, \mathrm{vol} / \mathrm{vol})$. A $20 \mu \mathrm{l}$ aliquot was then injected onto a Waters $\mu$ Bondapak phenyl column $(3.9 \times$ $150 \mathrm{~mm}$; Waters Associates, Milford, Mass.) in tandem with a Beckman Ultrasphere octyldecylsilane column $(5 \mu \mathrm{m}, 250 \times 4.6 \mathrm{~mm}$; Beckman Instruments, Palo Alto, Calif.) to separate $1 \mathrm{U}$ from $7 X$. Separation was consistently accomplished by use of the gradient elution profile shown in Fig. 2. The addition of a phenyl column improved the resolution of these metabolites, allowing satisfactory quantitation of both $1 \mathrm{U}$ and $7 \mathrm{X}$ on all samples tested. It was not unusual for the integrated $7 \mathrm{X}$ signal to exceed that of $1 \mathrm{U}$, and attempts to separate these metabolites by use of a phenyl column alone were unsuccessful. The identical protocol was performed with baseline urine samples that were spiked with known amounts of $1 \mathrm{X}$ and $1 \mathrm{U}$ standards, and the ultraviolet absorbance was monitored at $272 \mathrm{~nm}$. Standard curves relating the integrated signal values (relative to the internal standard, $N$-acetyl- $p$ amidophenol) versus known amounts of $1 \mathrm{X}$ and $1 \mathrm{U}$ standards, processed as above, were constructed. Subsequent urinary $1 \mathrm{X}$ and $1 \mathrm{U}$ concentrations were calculated by interpolation from the linear standard curve.

Phenotype determination. The acetylation phenotype of 20 individuals, previously tested with dapsone, was determined by use of the modified caffeine method. Subjects chosen were slow (eight), intermediate (eight), or rapid (four) metabolizers of dapsone. The dapsone method relies on determination of the ratio of $\mathrm{N}$-acetyldapsone to dapsone in serum, 3 hours after oral administration of the parent drug. ${ }^{21} \mathrm{~A} \mathrm{~N}$ acetyldapsone/dapsone ratio of 0.26 separates slow from rapid acetylators. 

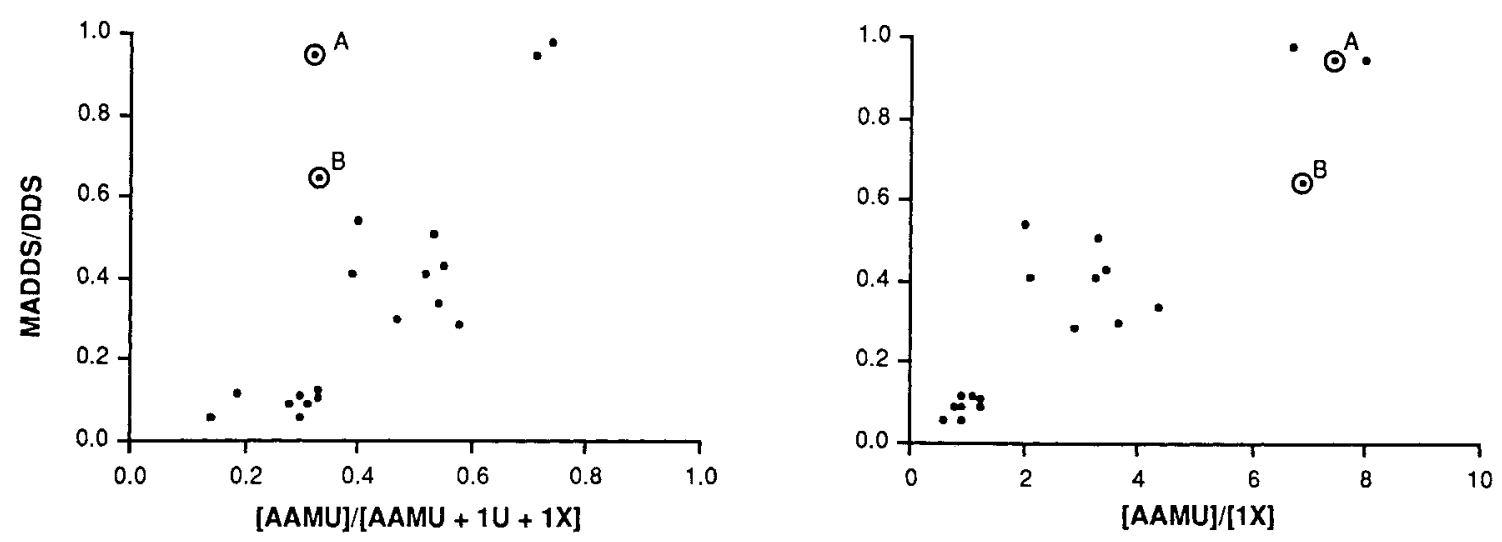

Fig. 3. Twenty individuals of known acetylator phenotype were tested with the modified caffeine method. The urinary molar ratios of (AAMU)/(AAMU $+1 U+1 \mathrm{X})$ and (AAMU)/(1X) are plotted against the $N$-acetyldapsone/dapsone (MADDS/DDS) ratio. Subjects A and B were discordant when the (AAMU)/(AAMU + $1 U+1 \mathrm{X}$ ) ratio was used because of concurrent administration of theophylline.
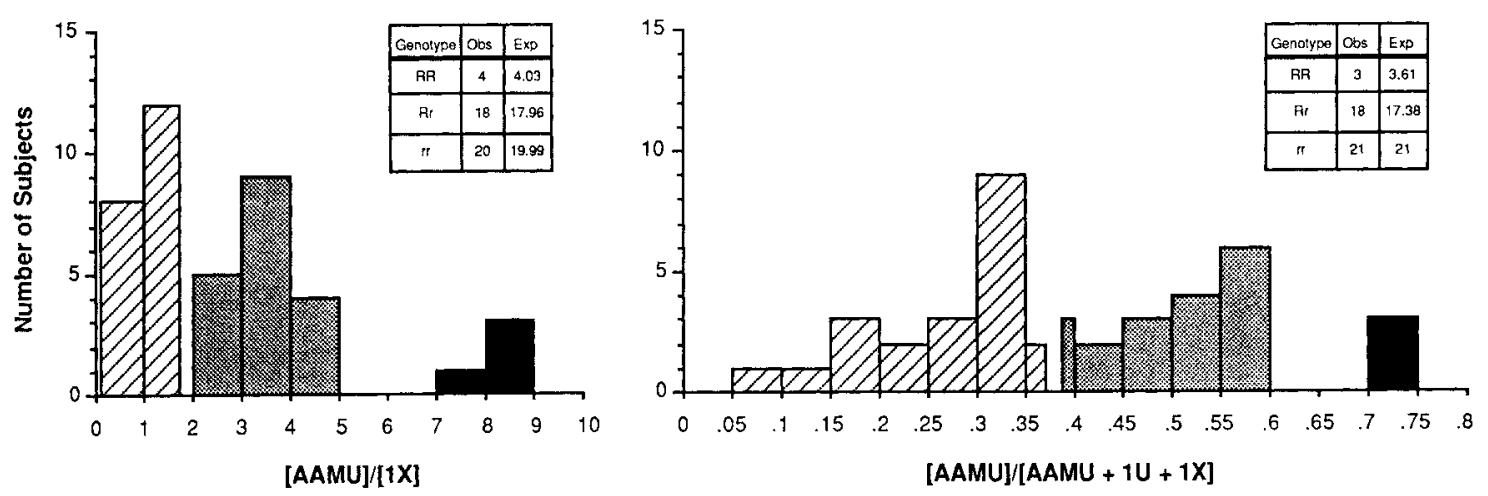

$\begin{aligned} Z & =\text { Homozygous Slow Acetylator } \\ & =\text { Heterozygous Rapid Acetylator } \\ & =\text { Homozygous Rapid Acetylator }\end{aligned}$

Fig. 4. Distribution histograms of a random population group of 42 unrelated individuals, comparing $(\mathrm{AAMU}) /(1 \mathrm{X})$ with $(\mathrm{AAMU}) /(\mathrm{AAMU}+1 \mathrm{U}+1 \mathrm{X})$ ratios. Antimodes at 1.82 and 6.60 for the former ratio and 0.38 and 0.66 for the latter ratio separates slow acetylators and homozygous rapid acetylators from heterozygous rapid acetylators. Inset figures indicate observed and expected genotypic values by application of the Hardy-Weinberg theory. The slow gene (q) frequency (S/total number $)^{1 / 2}$ was equal to 0.69 .

\section{RESULTS}

The separation of the methylurate and methylxanthine metabolites by use of the modified method is illustrated in Fig. 2. Standard curves plotting integrated signal values versus urinary metabolite concentrations were linear for AAMU (up to $80 \mathrm{mg} / \mathrm{L} ; r \geqslant 0.998$ ) and for $1 \mathrm{X}$ and $1 \mathrm{U}$ (up to $50 \mathrm{mg} / \mathrm{L} ; r \geqslant 0.996$ ). In- terday coefficients of variation were as follows: $6 \%$ to $12 \%$ for AAMU, $4 \%$ to $12 \%$ for $1 \mathrm{X}$, and $5 \%$ to $11 \%$ for $1 \mathrm{U}$.

The $N$-acetyldapsone/dapsone ratio is compared with the urinary molar ratio of (AAMU)/(AAMU + $1 \mathrm{U}+1 \mathrm{X}$ ) and (AAMU)/(1X) (Fig. 3). Arbitrary antimodes at 1.82 and 6.60 for the (AAMU)/(1X) ratio, 
Table I. Metabolic profiles of subjects and family pedigrees

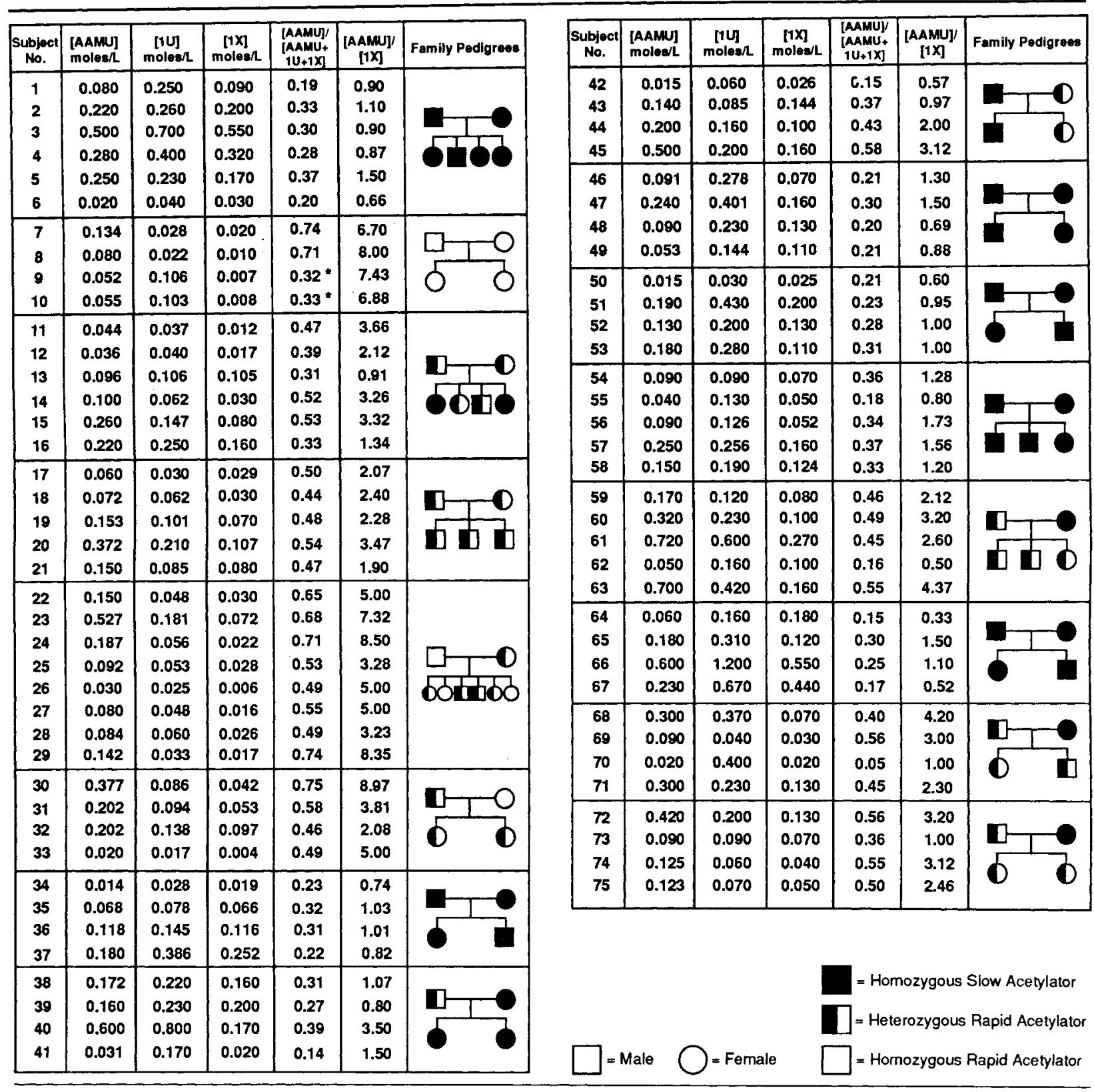

Urinary metabolite concentrations (mol/L), (AAMU)/(AAMU + IU + 1X), and (AAMU)/(1X) molar ratios and family pedigrees. For acetylation genotype determination in the family pedigrees, the molar ratio of (AAMU)/(IX) was used.

AAMU, 5-Acetylamino-6-amino-3-methyuracil; 1U, 1-methyluric acid; 1X, 1-methylxanthine.

*Subjects $\mathrm{A}$ and $\mathrm{B}$.

and 0.38 and 0.66 for the (AAMU)/(AAMU + $1 \mathrm{U}+1 \mathrm{X})$ ratio, separate slow, intermediate and rapid acetylators. There was close phenotypic correlation between the $N$-acetyldapsone/dapsone ratio and the urinary molar ratio of $(\mathrm{AAMU}) /(1 \mathrm{X})$, but the $(\mathrm{AAMU}) /(\mathrm{AAMU}+1 \mathrm{U}+1 \mathrm{X})$ ratio for two individuals (A and B) was distorted. A more comprehensive analysis of the trimodal acetylation patterns, observed by use of the modified caffeine method, was subse- quently undertaken by testing 42 unrelated healthy subjects. The trimodal distribution patterns of acetylation in this group is demonstrated by the histogram (Fig. 4), in which the observed values are consistent with those expected by application of the Hardy-Weinberg theory of population genetics.

Studies of informative families were also undertaken to further evaluate the potential genotyping capacity of this method. The urinary concentra- 
Table II. Observed matings from 16 marriages and resulting genotypes of offspring compared with expected values

\begin{tabular}{|c|c|c|c|c|c|c|c|c|c|}
\hline \multirow{3}{*}{$\begin{array}{c}\text { Genotype } \\
\text { matings }\end{array}$} & \multirow{3}{*}{$\begin{array}{c}\text { No. of } \\
\text { marriages }\end{array}$} & \multirow{3}{*}{$\begin{array}{l}\text { No. of } \\
\text { children }\end{array}$} & \multicolumn{3}{|c|}{ Observed } & \multicolumn{3}{|c|}{ Expected } & \multirow[b]{3}{*}{$\chi^{2}$ Values } \\
\hline & & & \multicolumn{2}{|c|}{ Rapid } & \multirow{2}{*}{$\frac{\text { Slow }}{r r}$} & \multicolumn{2}{|c|}{ Rapid } & \multirow{2}{*}{$\frac{\text { Slow }}{r r}$} & \\
\hline & & & $R R$ & $R r$ & & $R R$ & $R r$ & & \\
\hline $\mathrm{rr} \times \mathrm{rr}$ & 6 & 15 & 0 & 0 & 15 & 0 & 0 & 15 & $\ldots$ \\
\hline $\mathrm{Rr} \times \mathrm{Rr}$ & 2 & 7 & 0 & 5 & 2 & 1.75 & 3.50 & 1.75 & 2.42 (NS) \\
\hline $\mathrm{Rr} \times \mathrm{rr}$ & 5 & 11 & 0 & 8 & 3 & 0 & 5.5 & 5.5 & $2.28(\mathrm{NS})$ \\
\hline $\mathrm{RR} \times \mathbf{R r}$ & 2 & 8 & 2 & 6 & 0 & 4 & 4 & 0 & 2.00 (NS) \\
\hline $\mathrm{RR} \times \mathrm{RR}$ & 1 & 2 & 2 & 0 & 0 & 2 & 0 & 0 & - \\
\hline $\mathrm{RR} \times \mathrm{rr}$ & - & - & - & - & - & - & - & - & - \\
\hline
\end{tabular}

$\mathrm{RR}$, Homozygous rapid acetylator; $\mathrm{Rr}$, heterozygous rapid acetylator; $\mathrm{rr}$, slow acetylator; NS, not significant.

tion of relevant caffeine metabolites, individual $(\mathrm{AAMU}) /(\mathrm{AAMU}+1 \mathrm{U}+1 \mathrm{X})$ and $(\mathrm{AAMU}) /(1 \mathrm{X})$ ratios and family pedigree analysis are outlined in Table I. The observed genotypic matings and resulting offspring in 16 white families (75 individuals) are compared with those expected (Table II). The $\chi^{2}$ calculations reflect no significant difference between the observed values and those expected by classical Mendelian segregation.

\section{DISCUSSION}

When isonicotinic acid hydrazide (isoniazid) was first introduced as a tuberculostatic chemotherapeutic agent in the early $1950 \mathrm{~s},{ }^{22}$ it soon became apparent that considerable interindividual variation in the urinary excretion rates of the parent compound and its acetylated metabolite existed. ${ }^{23-25}$ This variation in isoniazid acetylation was later shown to be genetically determined ${ }^{1,26}$ and reflected varying activity of human liver $\mathrm{N}$-acetyltransferase. ${ }^{3}$ Peripheral neuritis was observed in slow metabolizers of isoniazid, ${ }^{24.27}$ and since then, several important associations between acetylator status and clinical disorders have been described. Drug toxicities of significance include the development of lupus erythematosus in slow metabolizers exposed to hydralazine ${ }^{28}$ and procainamide. ${ }^{29,30}$ Slow acetylators exposed to sulfasalazine exhibit cutaneous discoloration $^{31}$ and hematologic abnormalities, ${ }^{32}$ which are attributed to high levels of the sulfa metabolite, $N$ hydroxysulfapyridine. ${ }^{33,34}$ Statistical associations exist between slow acetylator phenotype and the development of bladder cancer ${ }^{35-37}$ A significant association also exists between the rapid acetylator phenotype and type I (insulin-dependent) diabetes mellitus in Europeans. ${ }^{38,39}$

To further evaluate the potential implications of the acetylation polymorphism and its effect on human response to drugs, especially in well-documented clinical situations, a rapid, noninvasive, and easily reproducible genotyping method would be desirable. In elucidation of the efficacy of the modified caffeine genotyping method, several problems were encountered that warrant amplification. Because of instability of AFMU, notably at pH 5 or greater, ${ }^{40}$ and its degradation over time, ${ }^{15}$ we proceeded to deformylate AFMU to the stable compound, ${ }^{20}$ AAMU, knowing this conversion had, in all probability, partially occurred in urine present in the bladder under physiologic $\mathrm{pH}$ conditions. ${ }^{20}$ Furthermore, because of incomplete resolution of AFMU by use of the single $C_{18}$ reverse-phase column, we elected to phenotype individuals by use of the $(\mathrm{AAMU}) /(\mathrm{AAMU}+1 \mathrm{U}+1 \mathrm{X})$ ratio, as described by Tang et al. ${ }^{20}$ It became apparent, however, that incomplete separations of $1 \mathrm{U}$ from $7 \mathrm{X}$ frequently occurred. This particular problem has been observed in other HPLC systems when attempting to separate 7methylxanthine and 1-methyluric acid. ${ }^{41}$ The addition of a phenyl column in advance of and in tandem with the $\mathrm{C}_{18}$ column resulted in satisfactory resolution of the $1 \mathrm{U}$ and $7 \mathrm{X}$ metabolites. The phenyl column was selected for the separation of these metabolites on the basis of previous success with this column for the separation of methylated purines. ${ }^{42}$

Two of our test subjects (A and B, Fig. 3) were receiving theophylline for bronchial asthma. Our observations suggested that, when testing subjects on theophylline, the acetylator genotype determination must be interpreted with caution when the $(\mathrm{AAMU}) /(\mathrm{AAMU}+1 \mathrm{U}+1 \mathrm{X})$ ratio is used. High urinary 1-methyluric acid (and coincidental low 1methylxanthine) levels in subjects taking theophylline have been described. ${ }^{43,44}$ An apparent slower acetylating capacity of these individuals is thus reflected by the (AAMU)/(AAMU $+1 U+1 \mathrm{X})$ molar ratio. Consequently, the alternative ratio of (AAMU)/(IX), which showed excellent correlation with the $\mathrm{N}$ acetyldapsone/dapsone ratio (Fig. 3), could be used to good effect in this situation. 
The results of family pedigree analysis (Tables I and II) are in keeping with Mendelian segregation patterns. The genotypic findings are consistent throughout and demonstrate trimodal distribution patterns of acetylation in this population group, as has been demonstrated previously with the caffeine method by Tang et al. ${ }^{20} \mathrm{As}$ several of the families studied included children with type I diabetes mellitus, the effect of high blood glucose on acetylator status might be questioned. Previous studies ${ }^{45}$ have shown no difference in acetylator status in subjects tested over widely differing blood glucose concentrations.

Problems with AFMU instability, particularly when stored in the bladder, are avoided when deformylation to AAMU is undertaken. ${ }^{19}$ Our data suggest that the ratio of $(\mathrm{AAMU}) /(1 \mathrm{X})$, based on family studies, reliably separates the three genotypes and is suggested as the ratio of choice for future investigation. It is also clear that, in this situation, measurement of urinary 1methyluric acid is no longer warranted because it offers no additional assistance when identification of the genotypes is attempted. The addition of a phenyl column (used in this study for accurate quantitation of $1 \mathrm{U}$ ) will, therefore, not be required when the urinary ratio of $(\mathrm{AAMU}) /(1 \mathrm{X})$ is used to determine the acetylator genotype. With each run for the size exclusion column taking 35 to 40 minutes, up to 12 individuals could be genotyped in a day.

Our study has reconfirmed the trimodal distribution patterns of acetylation in a population group with use of caffeine as a test drug, highlighted several problems in methods that were rectified, extended previous observations to include detailed family studies that demonstrate the expected Mendelian segregation patterns, and shown that the (AAMU)/(1X) ratio is preferable to the $(\mathrm{AAMU}) /(\mathrm{AAMU}+1 \mathrm{U}+1 \mathrm{X})$ ratio in distinguishing heterozygous from homozygous rapid acetylators. The data also suggest the ratio (AAMU)/(1X) can be used reliably when estimating acetylation capacity in patients taking theophylline, but this warrants further investigation.

\section{References}

1. Evans DAP, Manley KA, McKusick VA. Genetic control of isoniazid metabolism in man. Br Med J 1960;2:48591.

2. Weber WW, Brenner W. A filter paper method for determining isoniazid acetylator phenotype. Am J Hum Genet 1974;26:467-73.

3. Evans DAP, White TA. Human acetylation polymorphism. J Lab Clin Med 1964;63:394-403.

4. Schroder H, Evans DAP. The polymorphic acetylation of sulphapyridine in man. J Med Genet 1972;9:168-71.

5. Ellard GA. Absorption, metabolism and excretion of $\mathrm{di}(p$-aminophenyl)sulfone (dapsone) and $\operatorname{di}(p$ aminophenyl) sulfoxide in man. Br J Pharmacol 1966;26: 212-7.

6. Murray JF Jr, Gordon GR, Peters JH. A chromatographic-fluorometric procedure for the determination of nanogram quantities of antileprotic sulfones. J Lab Clin Med 1971;78:464-71.

7. Reidenberg MM, Drayer D, Levy M, Warner H. Polymorphic acetylation of procainamide in man. CLIN PHARMACOL THER 1975;17:722-30.

8. LeWalter J, Korallus U. Blood protein conjugates and acetylation of aromatic amines: New findings on biological monitoring. Int Arch Occup Environ Health 1985; 56:179-96.

9. Shear NH, Spielberg SP, Grant DM, Tang BK, Kalow W. Differences in metabolism of sufonamides predisposing to idiosyncratic toxicity. Ann Int Med 1986;105: $179-84$.

10. Curatolo PW, Robertson D. The health consequences of caffeine. Ann Int Med 1983;98(part I):641-53.

11. Lelo A, Miners JO, Tobson R, Birkett DJ. Assessment of caffeine exposure: caffeine content of beverages, caffeine intake, and plasma concentrations of methylxanthines. Clin Pharmacol Ther 1986;39:54-9.

12. Fink K, Adams WS, Pfleiderer W. A new urinary pyrimidine, 5-acetylamino-6-amino-3-methyluracil. J Biol Chem 1964;239:4250-6.

13. Callahan MM, Robertson RS, Arnaud MJ, Branfman AR, McComish M, Yesair DW. Human metabolism of [1-methyl- $\left.{ }^{-14} \mathrm{C}\right]$-and $\left[2-{ }^{14} \mathrm{C}\right]$-caffeine after oral älministrations. Drug Metab Dispos 1982;10:417-23.

14. Callahan MM, Robertson RS, Branfman AR, McComish MF, Yesair DW. Comparison of caffeine metabolism in three non-smoking populations after oral administration of radiolabeled caffeine. Drug Metab Dispos 1983;11:211-7.

15. Tang BK, Grant DM, Kalow W. Isolation and identification of 5-acetylamino-6-formylamino-3-methyluracil as a major metabolite of caffeine in man. Drug Metab Dispos 1983;11:218-20.

16. Branfman AR, McComish MF, Bruni RJ, Callahan MM, Robertson RS, Yesair DW. Characterization of diaminouracil metabolites of caffeine in human urine. Drug Metab Dispos 1983;11:206-10.

17. Grant DM, Tang BK, Kalow W. Polymorphic $N$ acetylation of a caffeine metabolite. CLIN PHARMACOL THER 1983;33:355-9.

18. Grant DM, Tang BK, Kalow W. A simple test for acetylator phenotype using caffeine. Br J Clin Pharmacol 1984;17:459-64

19. Tang BK, Zubovits T, Kalow W. Determination of acetylated caffeine metabolites by high-performance exclusion chromatography. J Chromatogr 1986;375:170-3.

20. Tang BK, Kadar D, Kalow W. An alternative test for 
acetylator phenotyping with caffeine. CLIN PHARMACOL THER 1987;42:509-13.

21. Carr K, Oates JA, Nies AS, Woosley RL. Simultaneous analysis of dapsone and monoacetyldapsone employing high performance liquid chromatography: a rapid method for determination of acetylator phenotype. $\mathrm{Br} \mathrm{J}$ Clin Pharmacol 1978;6:421-7.

22. Robitzek EH, Selikoff IJ, Ornstein GG, Chemotherapy of human tuberculosis with hydrazine derivatives of isonicotinic acid (preliminary report of representative cases). Q Bull Sea View Hosp 1952;13:27-51.

23. Hughes HB. On the metabolic fate of isoniazid. J Pharmacol Exp Ther 1953;109:444-52.

24. Hughes HB, Biehl JP, Jones AP, Schmidt LH. Metabolism of isoniazid in man as related to the occurrence of peripheral neuritis. Am Rev Tuberc 1954:70:266-73.

25. Bonicke R, Reif W. Enzymatische inaktivierung von isonicotinsaure hydrazide im menschlichen und tierschen organismus. Arch Exp Pathol Pharmakol 1953;220:32133.

26. Knight RA, Selin MJ, Harris WH. Genetic factors influencing isoniazid blood levels in humans. Trans Conf Chemother Tuberc 1959;18:52-8.

27. Devadatta S, Gangadharam PR, Andrews RH, et al. Peripheral neuritis due to isoniazid. Bull WHO 1960; 23:587-98

28. Perry HM, Tan EM, Carmody S, Sakamoto A. Relationship of acetyl transferase activity to antinuclear antibodies and toxic symptoms in hypertensive patients treated with hydralazine. J Lab Clin Med 1970;76:11425.

29. Davies DM, Beedie MA, Rawlins MD. Antinuclear antibodies during procainamide treatment and drug acetylation. Br Med J 1975;3:682-3.

30. Woosley RL, Drayer DE, Reidenberg M, Nies AS, Carr K, Oates JA. Effect of acetylator phenotype on the rate at which procainamide induces antinuclear antibodies and the lupus syndrome. New Engl J Med 1978;298: 1157-9.

31. Das KM, Eastwood MA, McManus JPA, Sircus W. Adverse reactions during salicylazosulfapyridine therapy and the relation with drug metabolism and acetylator phenotype. N Engl J Med 1973;289:491-6.

32. Pounder RE, Craven ER, Henthorn JS, Bannatyne JM. Red cell abnormalities associated with sulphasalazine maintenance therapy for ulcerative colitis. Gut 1975;16: 181-5.

33. Goodacre RL, Ali MAM, Vanderlinden B, Hamilton JD, Castelli M, Seaton T. Hemolytic anemia in patients receiving sulfasalazine. Digestion 1978;17:503-8.

34. Van Hees PA. Hemolysis during salicylazosulfapyridine therapy. Am J Gastroenterol 1979;70:501-6.

35. Lower GM Jr, Nilsson T, Nelson CE, Wolf H, Gamsky TE, Bryan ST. N-Acetyltransferase phenotype and risk in urinary bladder cancer: approaches in molecular epidemiology. Preliminary results in Sweden and Denmark. Environ Health Perspect 1979;29:71-9.

36. Wolf H, Lower GM, Bryan ST. Role of $N$ acetyltransferase phenotype in human susceptibility to bladder carcinogenic arylamines. Scand J Urol Nephrol 1980;14:161-5.

37. Weber WW. The acetylator genes and drug response. New York: Oxford University Press, 1987:207-26.

38. Mattila MJ, Tiitinen $H$. The rate of isoniazid inactivation in Finnish diabetic and non-diabetic patients. Ann Med Exp Fenn 1967;45:423-7.

39. Bodansky HJ, Drury PL, Cudworth AG, Evans DAP. Acetylator phenotypes and type I (insulin-dependent) diabetics with microvascular disease. Diabetes 1981;30: 907-10.

40. Lorenzo B, Reidenberg MM. Potential artifacts in the use of caffeine to measure acetylation phenotypes. $\mathrm{Br} \mathrm{J}$ Clin Pharmacol 1989;28:207-8.

41. Hotchkiss SA, Caldwell J. High performance chromatographic assay for theophylline and its major metabolites in human urine. J Chromatogr 1987;423:179-88.

42. Thielmann HW. Rapid determination of methylated purines in DNA treated with $N$-methyl- $N$-nitrosourea using high performance liquid chromatography. Cancer Lett 1979;6:311-7.

43. Cornish $\mathrm{HH}$, Christman AA. A study of the metabolism of theobromine, theophylline and caffeine in man. J Biol Chem 1957;228:315-23.

44. Thompson RD, Nagasana HT, Jenne JW. Determination of theophylline and its metabolites in human urine and serum by high pressure liquid chromatography. J Lab Clin Med 1974;84:584-93.

45. Suhardjono D, Boutagy J, Shenfield GM. The effect of glucose on acetylation status. Br J Clin Med 1986;22: 401-8. 